\title{
Comparison between latex and microscopic agglutination test for detection of human leptospiral antibodies
}

\author{
Ehsanollah Sakhaee, ${ }^{1}$ Mehdi Golchin, ${ }^{2}$ Zahra Davoodian ${ }^{1}$ \\ ${ }^{1}$ Department of Clinical Sciences; and ${ }^{2}$ Department of Pathobiology, Shahid Bahonar University of Kerman, Iran
}

\begin{abstract}
Leptospirosis, notably Weil's syndrome, is an often severe, acute febrile illness caused by microorganisms of the genus Leptospira. The microscopic agglutination test (MAT) is the basic method for the sero-diagnosis of leptospirosis, as the test has a high sensitivity and can be used for classification, but has some disadvantages. Therefore, we have explored latex agglutination test (LAT) for use as a practical and rapid for sero-diagnosis of human leptospirosis and compared the applicability of commercial tests MAT and LAT in the detection of specific antibodies against Leptospira interrogans in human.
\end{abstract}

\section{Introduction}

Leptospirosis is zoonotic disease caused by pathogenic Leptospira species. ${ }^{1}$ Incidence is the highest in tropical regions, including the Asia, Africa and Latin America. ${ }^{2}$ The laboratory diagnosis of human leptospirosis relies mainly on serological assays aimed at the detection of leptospiral antibodies in serum samples. Sensitivity and specificity of serological techniques used in the diagnosis of leptospirosis are different. To make a reliable diagnosis, it is necessary to use a number of techniques, together. ${ }^{3}$ The reference test for serologic diagnosis of leptospirosis is the microscopic agglutination test (MAT), wherein suspected sera are re-

Correspondence: Ehsanollah Sakhaee, Department of Clinical Sciences, School of Veterinary Medicine, Shahid Bahonar University of Kerman, Kerman, Iran.

Tel./Fax: +98.34.33257447.

E-mail: Ehsan_Sakhaee@yahoo.com

Key words: Human leptospirosis; latex agglutination test; microscopic agglutination test.

Acknowledgments: the authors thank Dr. Gholamreza Abdollahpour for his assistance in this study.

Funding: this research was funded by Research Council of Shahid Bahonar University of Kerman (grant number 94/423).

Conflict of interest: the authors declare no conflict of interest.

Received for publication: 13 November 2015.

Revision received: 10 February 2016.

Accepted for publication: 18 February 2016.

This work is licensed under a Creative Commons Attribution NonCommercial 4.0 License (CC BY-NC 4.0).

CCopyright E. Sakhaee et al., 2016

Licensee PAGEPress, Italy

Italian Journal of Medicine 2016; 10:219-222

doi:10.4081/itjm.2016.673 acted with live antigen of leptospiral and then examined under dark-field microscopy. The end point titer is determined as the highest serum dilution showing approximately $50 \%$ free, unagglutinated leptospires compared to the control. Considerable effort is required to reduce the subjective effect of observer variation. The MAT has some disadvantages and is a complex test to perform and interpret which indicate the need for an alternative test for routine diagnosis of leptospirosis. One of the problems is its use of live organisms as antigens. This requires the continuous culture and handling of the bacteria in laboratories. Other drawbacks of MAT include the continuous risk of contamination of the antigen cultures, a high degree of cross-reaction between different serogroups, and the subjective assessment of results can also make quality assurance of the MAT difficult. ${ }^{4}$ Moreover, the repeated subculture of large numbers of serovars had some risks for laboratory technicians. Latex agglutination test (LAT) has been explored for use as a practical and rapid diagnostic technique of human leptospirosis and compared the applicability of MAT and LAT in the detection of specific antibodies against Leptospira interrogans in human.

\section{Ethical approval}

All ethical considerations were considered carefully, and all procedures performed in studies involving human participants were approved by the Ethics Committee of Kerman University of Medical Sciences, Kerman, Iran.

\section{Materials and Methods}

\section{Sample collection and processing}

A total of 213 serum samples (62 men and 151 women) were collected from Kerman province, from December (2014) to February (2015). Sera were sep- 
arated by centrifugation of blood at $3000 \mathrm{~g}$ for $10 \mathrm{~min}$ at room temperature and transferred into $1.5 \mathrm{~mL}$ sterile micro tube (Eppendorf) and were kept at $-20^{\circ} \mathrm{C}$ until required. These samples were submitted to the Leptospira Research Laboratory of the Faculty of Veterinary Medicine at the University of Tehran, Iran.

\section{Microscopic agglutination test}

Microscopic agglutination test was performed mainly as described by Turner (1968) with some modification as follows: a 10-day-old culture of $L$. interrogans in liquid medium was used as antigen. The density of leptospires was adjusted to $2 \times 10^{8}$ leptospires/mL. ${ }^{5}$ Five reference strains of Leptospira interrogans which were used as antigen includes: hardjo, pomona, icterohaemorrhagiae, grippotyphosa, and canicola. All serum samples were serially diluted, starting from 1 in 50 dilution, using 2-fold dilution (1 in $100,200,400,800$ and 1600$)$. Then, $10 \mu \mathrm{L}$ of serum dilution was added to $10 \mu \mathrm{L}$ of appropriate antigen on a microscopic slide, and incubated at $30^{\circ} \mathrm{C}$ for $90 \mathrm{~min}$. Finally, the slide was examined under dark-field microscope (Olympus BX50; Olympus Corp., Tokyo, Japan). One antigen control and two (positive and negative) standard serum controls were used each time. Titers 1:100 or greater were considered positive. The end-point titer was determined as the highest serum dilution showing agglutination of at least $50 \%$ of the leptospires.

\section{Latex agglutination test}

The latex agglutination test assay was performed mainly as described by Kelen (1960) with a commercial kit (Zist Faravard Pars, Guilan, Iran) by placing one drop of a serum sample on a white agglutination card. ${ }^{6}$ Subsequently, the serum drops were mixed with equal volumes $(10 \mu \mathrm{L})$ of control and test latex. Latex and serum were mixed with the disposable tip of a pipette. The card was then shaken gently for $5 \mathrm{~min}$. Samples were considered negative if no agglutination was observed within 2 min, positive when agglutination became visible less than $1 \mathrm{~min}$ and suspected when slight agglutination visible between 1 and $2 \mathrm{~min}$.

\section{Results}

\section{Microscopic agglutination test}

Number and frequency of positive and negative samples were shown in each sex among 213 sera in Table 1. Antibodies were detected at least against one serovar of Leptospira interrogans in 21 sera (9.86\%) among 213 samples at dilution 1:100 or greater. Positive titers against more than one serovar were detected in 4 sera of the positive samples (Table 1). Therefore, there were 25 positive reactions against different serovar of L. interrogans. Positive titers were recorded against serovar pomona (11 samples), hardjo (8 samples), grippotyphosa (3 samples), icterohaemorrhagiae (2 samples) and canicola (1 samples) (Tables 2 and 3 ).

\section{Latex agglutination test}

Table 4 shows number and frequency of positive, negative and suspected samples in each sex among 213 sera by LAT.

Comparison between the MAT and LAT showed that some positive sera by MAT, were negative by

Table 1. Number and frequency of positive and negative samples in men and women among 213 sera.

\begin{tabular}{lccc}
\hline Sera & Positive samples & Negative samples & Total \\
\hline Men & $9(4.22 \%)$ & $53(24.88 \%)$ & $62(29.10 \%)$ \\
\hline Women & $12(5.63 \%)$ & $139(65.27 \%)$ & $151(70.90 \%)$ \\
\hline Total & $21(9.85 \%)$ & $192(90.15 \%)$ & $213(100 \%)$ \\
\hline
\end{tabular}

Table 2. Frequency and number of positive sera by microscopic agglutination test at a dilution 1:100, in terms of number of serovars among 213 samples.

\begin{tabular}{lcc}
\hline Number of serovars & Number of positive sera & Frequency (\%) \\
\hline One serovar & 17 & 7.98 \\
\hline Two serovars & 2 & 0.94 \\
\hline Three serovars & 1 & 0.47 \\
\hline Four serovars & 1 & 0.47 \\
\hline Total & 21 & 9.86 \\
\hline
\end{tabular}


LAT and some positive or suspected sera by LAT were negative by MAT.

The kappa statistic method was used to determine the overall agreement value between MAT and LAT. According to Table 5, number of observed agreement is 198 (92.96\% of the observations) and number of agreements expected by chance is 167.9 (78.83\% of the observations). Accordingly, $0.512<\kappa$ value \pm standard error $(\mathrm{SE})=0.667 \pm 0.079<0.823(95 \%$ confidence interval), so, there is Good agreement (high correlation) between two tests. A number of serological techniques are used in the diagnosis of leptospirosis, each having its own sensitivity and specificity. According to Table 6 , the test has a sensitivity of $85.71 \%$, specificity of $93.75 \%$, positive predictive value of $60 \%$ and a negative predictive value of $98.36 \%$, and the $\kappa$ value $\pm \mathrm{SE}$ of agreement is $0.667 \pm 0.079$.

\section{Discussion}

Leptospirosis is now identified as one of the emerging infectious diseases, exemplified by recent large outbreaks in Nicaragua, ${ }^{7}$ Brazil, India, ${ }^{8}$ Southeast Asia, the United States, ${ }^{9}$ and most recently in Malaysia. ${ }^{10}$

In leptospirosis, antibodies usually appear within

Table 3. Number and frequency of serum samples with positive titer against each serovar, at different dilutions.

\begin{tabular}{|c|c|c|c|c|c|}
\hline Serovar & $\begin{array}{c}1: 100 \\
\text { Number (\#) }\end{array}$ & $\begin{array}{c}1: 200 \\
\text { Number (\#) }\end{array}$ & $\begin{array}{c}\text { Dilutions } \\
\text { 1:400 } \\
\text { Number (\#) }\end{array}$ & $\begin{array}{c}\text { 1:800 } \\
\text { Number (\#) }\end{array}$ & $\begin{array}{c}1: 1600 \\
\text { Number (\#) }\end{array}$ \\
\hline pomona & $11(44)$ & $2(8)$ & $1(4)$ & $1(4)$ & $1(4)$ \\
\hline hardjo & $8(32)$ & $1(4)$ & $0(0)$ & $0(0)$ & $0(0)$ \\
\hline grippotyphosa & $3(12)$ & $0(0)$ & $0(0)$ & $0(0)$ & $0(0)$ \\
\hline icterohaemorrhagiae & $2(8)$ & $0(0)$ & $0(0)$ & $0(0)$ & $0(0)$ \\
\hline canicola & $1(4)$ & $0(0)$ & $0(0)$ & $0(0)$ & $0(0)$ \\
\hline Total & $25(100)$ & $3(12)$ & $1(4)$ & $1(4)$ & $1(4)$ \\
\hline
\end{tabular}

\#, frequency (\%) of positive serum samples.

Table 4. Number and frequency of positive and negative samples in each sex among 213 sera.

\begin{tabular}{lcccc}
\hline Sera & Positive samples & Negative samples & Suspected samples & Total \\
\hline Men & $7(3.28 \%)$ & $50(23.47 \%)$ & $5(2.35 \%)$ & $62(29.10 \%)$ \\
\hline Women & $10(4.69 \%)$ & $133(62.44 \%)$ & $8(3.75 \%)$ & $151(70.90 \%)$ \\
\hline Total & $17(7.97 \%)$ & $183(85.91 \%)$ & $13(6.10 \%)$ & $213(100 \%)$ \\
\hline
\end{tabular}

Table 5. Number of positive and negative serum samples of 213 samples by microscopic and latex agglutination test.

\begin{tabular}{lccc}
\hline & LAT positive or suspected & LAT negative & Total \\
\hline MAT positive & 18 & 3 & 21 \\
\hline MAT negative & 12 & 180 & 192 \\
\hline Total & 30 & 183 & 213 \\
\hline
\end{tabular}

LAT, latex agglutination test; MAT, microscopic agglutination test.

Table 6. The test sensitivity, specificity, positive predictive value and negative predictive value.

\begin{tabular}{lccc}
\hline Sensitivity (\%) & $\begin{array}{c}\text { Specificity } \\
(\%)\end{array}$ & $\begin{array}{c}\text { Positive predictive } \\
\text { value (\%) }\end{array}$ & $\begin{array}{c}\text { Negative predictive } \\
\text { value (\%) }\end{array}$ \\
\hline 85.71 & 93.75 & 60 & 98.36 \\
\hline
\end{tabular}


less than one week after the onset of the clinical findings and in a significant proportion of patients, antibodies persist in detectable quantities for many months. ${ }^{11}$ Serological testing is the most widely used means for diagnosis of leptospirosis, and the MAT is the gold standard serological test. The MAT using live bacteria is the most widely used serological test. It is the reference test against which all other serological tests. The sensitivity of the MAT can be improved by using local serovars rather than reference strains, but reference strains assist in the interpretation of results between laboratories. The specificity of the MAT is good, therefore, there is not cross-react with Leptospira to a significant extent. However, there is significant serological cross-reactivity between serovars and serogroups of Leptospira and an animal infected with one serovar is likely to have antibodies against the infecting serovar that cross-reacts with other serovars in the MAT. ${ }^{12}$ The major advantage of the MAT is its high specificity and important disadvantages are the need for facilities to culture and maintain panels of live leptospires. Furthermore, the test is both technically demanding and time-consuming. ${ }^{13}$ The results of present study show the same efficacy between the MAT and LAT and demonstrate almost equally high sensitivities of the latex agglutination assay for detecting infections (Table 5). These results show that the latex agglutination assay will be a valuable tool in the diagnosis of leptospirosis. Mentioned assay is simple and rapid to perform, and can be performed without the need for training or special or expensive equipment. This method has a reasonable sensitivity and specificity, and results are in agreement with those of the MAT, in particular for samples collected early in the disease. So, these test characteristics make the assay suitable for use in situations where facilities or resources to perform more complicated tests are not available. The method also gives a quick result, which can be important in the management of patients, especially when attention must be given to a large number of patients.

\section{References}

1. Van Hooste W. Leptospirosis - Review of the literature. Tijdschr Geneeskd 2007;63:917-28.

2. Pappas G, Papadimitriou P, Siozopoulou V, et al. The globalization of leptospirosis: worldwide incidence trends. Int J Infect Dis 2008;12:351-7.

3. Angela P, Brandao D, Camargo D, et al. Macroscopic agglutination test for rapid diagnosis of human leptospirosis. J Clin Microbiol 1998;36:3138-42.

4. Surujballi OM, Mallory M. An indirect enzyme-linked immunosorbent assay for the detection of bovine antibodies to multiple leptospira serovars. Can J Vet Res 2004;68:1-6.

5. Turner LH. Leptospirosis, II, serology. Trans R Soc Trop Med Hyg 1968;62:880-99.

6. Kelen AE, Labzoffsky NA. Studies on latex agglutination test for leptospirosis. Can J Microbiol 1960;6: 463-73.

7. Brandling-Bennett AD, Pinheiro F. Infectious diseases in Latin America and the Caribbean: are they really emerging and increasing? Emerg Infect Dis 1996;2: 59-61.

8. World Health Organization. Leptospirosis, India: report of the investigation of a post-cyclone outbreak in Orissa. Wkly Epidemiol Rec 2000;75:217-23.

9. Centers for Disease Control and Prevention. Update: leptospirosis and unexplained acute febrile illness among athletes participating in triathlons - Illinois and Wisconsin. Morb Mortal Wkly Rep 1998;47:673-6.

10. Evans M, Baranton G. Leptospirosis outbreak in Eco Challenge 2000 participants. Eurosurveillance Weekly 2000;4:000921. Available from: http://www.eurosurv. org/2000/000921.htm

11. Farr RW. Leptospirosis. Clin Infect Dis 1995;21:1-8.

12. The World Organisation for Animal Health (OIE). Leptospirosis (version adopted in May 2014); Chapter 2.1.12. In: OIE, ed. Manual of diagnostic tests and vaccines for terrestrial animals. Paris: OIE. Available from: http://www.oie.int/fileadmin/Home/eng/Health_ standards/tahm/2.01.12_LEPTO.pdf

13. World Health Organization. Human leptospirosis: guidance for diagnosis, surveillance and control. Geneva: World Health Organization; 2013. 